\title{
Women in clinical autonomic research and the autonomic societies: how far have we come in thirty years?
}

\author{
Chloe E. Taylor ${ }^{1} \cdot$ Amy C. Arnold $^{2} \cdot$ Alessandra Fanciulli $^{3} \cdot$ Federica Provini $^{4} \cdot$ Qi Fu $^{5,6} \cdot$ Vaughan G. Macefield $^{7}$. \\ Debra E. Weese-Mayer ${ }^{8,9} \cdot$ Cyndya Shibao $^{10} \cdot$ Nisha Charkoudian $^{11} \cdot$ Victoria E. Claydon $^{12}$
}

Received: 2 January 2021 / Accepted: 4 January 2021 / Published online: 17 January 2021

(c) Springer-Verlag GmbH Germany, part of Springer Nature 2021

Clinical Autonomic Research, established in 1991, has played an important role in addressing health issues for women over the past 30 years, highlighting meaningful differences in autonomic function in health and disease between women and men [17]. For instance, young women are five times more likely to suffer from orthostatic intolerance compared to young men $[1,6]$. One of the major contributions of autonomic physicians and scientists has been to recognize, quantify, and treat these disorders for women whose symptoms were otherwise ignored or minimized. Accordingly, the autonomic community, including the American Autonomic Society (AAS), the European Federation of Autonomic Societies (EFAS) and the International Society for Autonomic Neuroscience (ISAN), has made a huge impact on the lives of thousands of women.

Clinical Autonomic Research is the official journal of the AAS and the EFAS. We are proud of our longstanding relationship with these societies, and our united approach to supporting women in a clinical context. It is also important to consider, however, the roles that autonomic societies

Chloe E. Taylor

C.Taylor@westernsydney.edu.au

1 School of Health Sciences, Western Sydney University, Sydney, Australia

2 Department of Neural and Behavioral Sciences, Pennsylvania State University College of Medicine, Hershey, PA, USA

3 Department of Neurology, Medical University of Innsbruck, Innsbruck, Austria

4 IRCCS Istituto Delle Scienze Neurologiche Di Bologna, UOC Clinica Neurologica NeuroMet, Ospedale Bellaria, Via Altura 3, 40139 Bologna, Italy

5 Women's Heart Health Laboratory, Institute for Exercise and Environmental Medicine at Texas Health Presbyterian Hospital, Dallas, TX, USA

6 The University of Texas Southwestern Medical Center, Dallas, TX, USA and journals play from a professional perspective, specifically by supporting the involvement of women in autonomic research. Over the past 30 years, both women and men have contributed importantly to increased understanding and enhanced treatment of people with autonomic dysfunction. Our goal in this editorial is to give a brief overview of the evolution of women's involvement in Clinical Autonomic Research and the major autonomic societies.

To determine the involvement of women as authors of articles published in Clinical Autonomic Research we determined the number and percentages of published articles with (i) at least one female author, (ii) at least one male author, (iii) a female first author, and (iv) a female last author, which typically represents the senior or lead author. To achieve an overview of the changes in representation over the 30 years since the journal's inception, we arbitrarily focused on six specific years selected at 5-year intervals: 1994, 1999, 2004, 2009, 2014, and 2019. We also included data from 2020 due to reports on the disproportionately negative impact of the COVID-19 pandemic on women in science $[11,14]$. For

7 Baker Heart and Diabetes Institute, Melbourne, Australia

8 Division of Autonomic Medicine, Center for Autonomic Medicine in Pediatrics (CAMP), Department of Pediatrics, Ann \& Robert H. Lurie Children's Hospital of Chicago and Stanley Manne Children's Research Institute, Chicago, IL, USA

9 Department of Pediatrics, Pediatric Autonomic Medicine, Northwestern University Feinberg School of Medicine, Chicago, IL, USA

10 Division of Clinical Pharmacology and Autonomic Dysfunction Center, Vanderbilt University Medical Center, Nashville, TN, USA

11 U.S. Army Research Institute of Environmental Medicine, Natick, MA, USA

12 Department of Biomedical Physiology and Kinesiology, Simon Fraser University, Burnaby, BC, Canada 
each year, metrics were quantified for all articles combined, as well as for different article types: original research, editorials, reviews, and 'other' (including letters to the editor, short communications, case studies, tributes, guest lectures, meeting reports). We also determined the number of men and women in leadership positions for the following boards and societies: Clinical Autonomic Research editorial board (1991-2020), AAS board of directors (1992-2020), the EFAS council (1998-2020), and ISAN executive committee (1997-2019). Membership data were requested for all three main autonomic societies, but were only available for the AAS (1996-2020). We used the term "gender" because we are investigating gender-based disparities within a sociocultural context. We recognise that gender is not binary and is self-identified, but had to use assigned binary terms ("women/female" and "men/male") because of the limited information available. We assigned gender as follows: (i) based on self-identification in society membership lists, or use of a gendered prefix (Mr., Mrs., Ms.); (ii) based on an internet search using the author's name and institutional affiliation, with gender determination based on pronoun usage (e.g., she/he), gender noted on their institutional web page, or clinician listing websites; and, (iii) based on their photograph, typical gender association with the first name, or knowledge of the individual through professional acquaintance. For two AAS members and authors of one publication, gender could not be reasonably determined and so they were excluded.

The absolute number of publications in Clinical Autonomic Research authored by women has increased over time, largely reflecting increases in the overall number of published articles. The percentage of publications with at least one female author was $49 \%$ in 1994, rising to $69 \%$ in 2019 (Fig. 1a). Between $88-100 \%$ of papers had at least one male author during this period. The percentage of publications with a female first author has consistently been below $50 \%$ over the last 30 years. The trend for women to be underrepresented is even more marked when considering last/senior authors. In 2019, the percentage of publications in Clinical Autonomic Research with a female last author was $27 \%$, similar to the data in 1994 , when $28 \%$ of senior authors were women. When considering original research
Fig. 1 Representation of women in autonomic research. In terms of publications in Clinical Autonomic Research, women were consistently underrepresented in authorship when considering all article types (a) and original research articles (b). This is particularly stark when considering representation of women in the leadership roles represented by first and senior authorship. Women were also underrepresented in leadership positions such as the ISAN executive committee, EFAS board, and Clinical Autonomic Research editorial board, although parity was recently achieved for the AAS board (c). The percentage of women members of the AAS has risen over the past few decades, achieving parity in recent years $(\mathbf{d})$
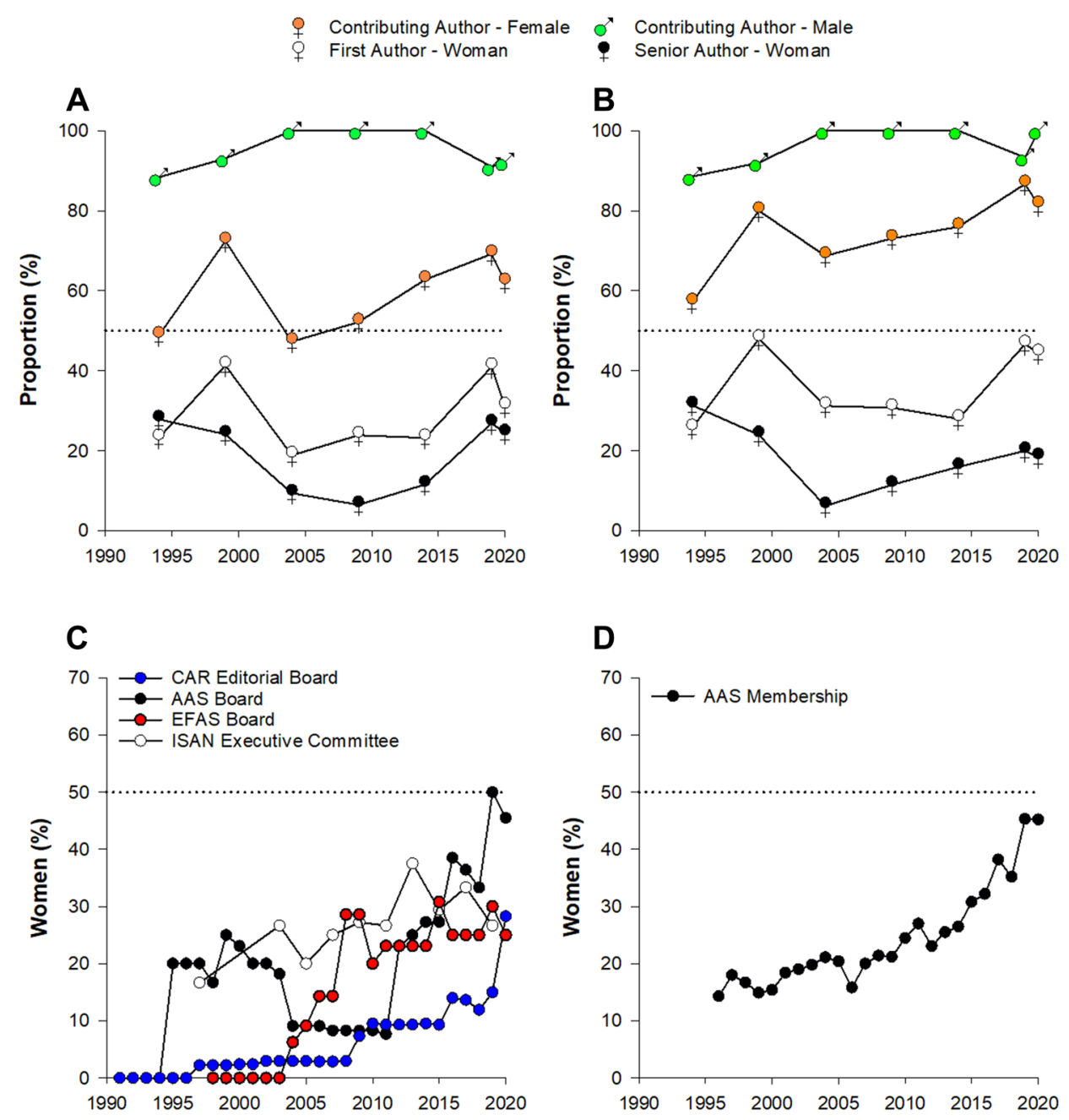
articles (Fig. 1b), the percentage with at least one female author ranged from 57\% in 1994 to $87 \%$ in 2019, compared to $89-100 \%$ for men over the same period. Women represented $47 \%$ of first authors in 2019 , but only $20 \%$ of senior authors. The most striking disparity was seen in editorials. In the years that were surveyed, there was no more than one editorial per year by a female senior author, with the exception of 2020 when there were four. Of the 55 editorials published across the years surveyed, six (11\%) were authored by female senior authors, and $49(89 \%)$ by male.

For the year 2020, there is evidence of a small reduction in the percentage of published articles with at least one female author in Clinical Autonomic Research (62\%) compared with 2019 (69\%). The trend was consistent for all article types except editorials and is compatible with evidence from other journals indicating that the percentage of publications from women has dropped during the COVID-19 pandemic [11].

After its foundation in 1991, the Clinical Autonomic Research editorial board was exclusively men, until Prof. Felicia Axelrod, founder of the New York University Dysautonomia Center, joined in 1997 [2]. Prof. Axelrod was the only woman on the Clinical Autonomic Research editorial board for the next 12 years. Currently, women represent $28 \%$ of the 46-member Clinical Autonomic Research editorial board, which is significantly higher than in preceding years, but far from parity (Fig. 1c). Prof. Qi Fu was recently appointed an associate editor of Clinical Autonomic Research, the first woman so appointed [8]. Despite the low numbers of women on the Clinical Autonomic Research editorial board, those present have been actively studying women's issues in the context of autonomic neuroscience. A recent Clinical Autonomic Research special issue highlighting sex differences in autonomic cardiovascular control was spearheaded by women leaders in the field who are also members of the Clinical Autonomic Research editorial board [17].

Likewise, the AAS board of directors was initially composed entirely of men with a minimal female representation (below 30\%) until 2015. Prof. Axelrod was a founding member of AAS and the only woman serving as president (2001-2002) during its 30-year history. In the last decade, there has been a purposeful effort to increase the representation of women on the AAS board, which has recently achieved parity, as well as the creation of the women's interest group led by Dr. Amanda Peltier.

The EFAS board, which includes representatives from European national autonomic societies, had no women included for the first 6 years until Prof. Anne Pavy-Le Traon joined in 2004. Throughout EFAS history, women remained in the minority within the EFAS board (Fig. 1C), but covered key positions, reaching parity in the 2020 election of the EFAS council officers. Women have also played an important role in EFAS scientific and educational agendas, coordinating the dysautonomia rating scale for Parkinson disease $[15,16]$, spearheading consensus papers on neurogenic supine hypertension produced conjointly with the AAS [5, 9] and leading the EFAS educational curriculum initiated by Prof. Isabel Rocha in 2010.

At the inaugural meeting of ISAN in 1997, the ISAN executive committee comprised eleven men and one woman, Prof. Elspeth McLachlan, but the proportion of women has progressively increased (Fig. 1c), reaching a peak of $38 \%$ in 2013. Prof McLachlan has been a key figure in studying ganglionic neurophysiology and the autonomic consequences of spinal cord injury [13], and initially served as International Liaison for ISAN. Prof. Janet R. Keast is a leading authority on autonomic innervation of the female pelvic organs [10], and served as ISAN president from 2007-2009, the only woman who has been elected to this role.

While we were not able to analyze historical data for EFAS and ISAN, current AAS statistics suggest that we are approaching parity in the membership ( $n=554 ; 68 \%$ established researchers/clinicians, $20 \%$ trainees; Fig. 1d). In the late 1990s, the proportion of women AAS members was consistently below $20 \%$, but over the last decade, female representation in the membership has increased. In 2020, women represented $45 \%$ of the AAS membership.

We here highlight historical discrepancies, acknowledge recent progress and call for further action to address disparities in the autonomic community, both from the perspective of publications in our journal and leadership in relevant societies. Over the last 30 years, persistently poor representation of women has been the norm, with only very recent drives to address this.

Current AAS membership statistics suggest there is currently no "pipeline" issue with women joining the field of autonomic research. Our results indicate that gender disparities are less evident when it comes to contributing to research in our field and more prominent with regard to positions of leadership and influence. This may reflect a combination of a lack of effective advocacy and leadership opportunities, implicit bias, and gendered roles at work and home [12]. We seek greater recognition of women and their contributions to the field, with more opportunities to be involved in leadership roles. It will take a conscious effort to achieve parity on editorial boards and executive committees. When women do get into these positions of influence, we ask that they reflect on their own biases to ensure that we continue to work toward a more equitable and diverse environment. Certainly, it is not "only" the responsibility of women to promote other women, but being a woman in leadership does not exclude one from the effort to promote other women. In this context, sponsorship of women scientists becomes paramount in their advancement toward leadership roles, and greater visibility of women in all leadership positions will 
further enhance representation by empowering others. These efforts will be particularly important if we are to mitigate the disproportionately negative impact of the COVID-19 pandemic on women [4].

To ensure that future analyses can be performed and more accurately reflect gender across the spectrum, we suggest that journals and societies request information on this from authors and membership. Additionally, it will be important to explore the intersectionality of gender disparities with other underrepresented groups [3, 7]. We need to ensure that consideration of equity issues does not focus solely on percentages of diverse individuals, but also their sense of inclusion.

In summary, we are making significant progress to address disparities in Clinical Autonomic Research and the autonomic societies, but there is still much work to be done. There are many outstanding women in our field for whom the opportunity to serve in leadership positions will strengthen and diversify the current leadership. We encourage all in the field to reflect on their own roles and to challenge themselves to make an extra effort in coming years, as it is only through proactive approaches that we will achieve equity in the field of autonomic research.

Funding None.

\section{Compliance with ethical standards}

Conflict of interest None.

\section{References}

1. Ali YS, Daamen N, Jacob G, Jordan J, Shannon JR, Biaggioni I, Robertson D (2000) Orthostatic intolerance: a disorder of young women. Obstet Gynecol Surv 55:251-259

2. Axelrod FB (2006) A world without pain or tears. Clin Auton Res 16:90-97

3. Brown N, Leigh J (2018) Ableism in academia: where are the disabled and ill academics? Disabil Soc 33:985-989

4. Cardel MI, Dean N, Montoya-Williams D (2020) Preventing a secondary epidemic of lost early career scientists. effects of COVID-19 pandemic on women with children. Ann Am Thorac Soc 17:1366-1370

5. Fanciulli A, Jordan J, Biaggioni I, Calandra-Buonaura G, Cheshire WP, Cortelli P, Eschlboeck S, Grassi G, Hilz MJ, Kaufmann H, Lahrmann H, Mancia G, Mayer G, Norcliffe-Kaufmann L, PavyLe Traon A, Raj SR, Robertson D, Rocha I, Struhal W, Thijs R, Tsioufis KP, van Dijk JG, Wenning GK (2018) Consensus statement on the definition of neurogenic supine hypertension in cardiovascular autonomic failure by the American Autonomic Society (AAS) and the European Federation of Autonomic Societies (EFAS): endorsed by the European Academy of Neurology (EAN) and the European Society of Hypertension (ESH). Clin Auton Res 28:355-362

6. Freeman R, Wieling W, Axelrod FB, Benditt DG, Benarroch E, Biaggioni I, Cheshire WP, Chelimsky T, Cortelli P, Gibbons CH, Goldstein DS, Hainsworth R, Hilz MJ, Jacob G, Kaufmann H, Jordan J, Lipsitz LA, Levine BD, Low PA, Mathias C, Raj SR, Robertson D, Sandroni P, Schatz I, Schondorff R, Stewart JM, van Dijk JG (2011) Consensus statement on the definition of orthostatic hypotension, neurally mediated syncope and the postural tachycardia syndrome. Clin Auton Res 21:69-72

7. Ginther DK, Schaffer WT, Schnell J, Masimore B, Liu F, Haak LL, Kington R (2011) Race, ethnicity, and NIH research awards. Science 333:1015-1019

8. Hissen SL, Fu Q (2020) Neural control of blood pressure during pregnancy in humans. Clin Auton Res 30:423-431

9. Jordan J, Fanciulli A, Tank J, Calandra-Buonaura G, Cheshire WP, Cortelli P, Eschlboeck S, Grassi G, Hilz MJ, Kaufmann H, Lahrmann H, Mancia G, Mayer G, Norcliffe-Kaufmann L, PavyLe Traon A, Raj SR, Robertson D, Rocha I, Reuter H, Struhal W, Thijs RD, Tsioufis KP, Gert van Dijk J, Wenning GK, Biaggioni I (2019) Management of supine hypertension in patients with neurogenic orthostatic hypotension: scientific statement of the American Autonomic Society, European Federation of Autonomic Societies, and the European Society of Hypertension. J Hypertens 37:1541-1546

10. Keast JR (1999) Unusual autonomic ganglia: connections, chemistry, and plasticity of pelvic ganglia. Int Rev Cytol 193:1-69

11. Kibbe MR (2020) Consequences of the COVID-19 pandemic on manuscript submissions by women. JAMA Surg 155:803-804

12. Magliano DJ, Macefield VG, Ellis TM, Calkin AC (2020) Addressing gender equity in senior leadership roles in translational science. ACS Pharmacol Transl Sci 3:773-779

13. McLachlan EM (2007) Diversity of sympathetic vasoconstrictor pathways and their plasticity after spinal cord injury. Clin Auton Res 17:6-12

14. Myers KR, Tham WY, Yin Y, Cohodes N, Thursby JG, Thursby MC, Schiffer P, Walsh JT, Lakhani KR, Wang D (2020) Unequal effects of the COVID-19 pandemic on scientists. Nat Hum Behav 4:880-883

15. Pavy-Le Traon A, Amarenco G, Duerr S, Kaufmann H, Lahrmann H, Shaftman SR, Tison F, Wenning GK, Goetz CG, Poewe W, Sampaio C, Schrag A, Stebbins GT, Rascol O (2011) The movement disorders task force review of dysautonomia rating scales in Parkinson's disease with regard to symptoms of orthostatic hypotension. Mov Disord 26:1985-1992

16. Pavy-Le Traon A, Cotterill N, Amarenco G, Duerr S, Kaufmann H, Lahrmann H, Tison F, Wenning GK, Goetz CG, Poewe W, Sampaio C, Schrag A, Rascol O, Martinez-Martin P, Stebbins GT, Members of the MDSCoRSD (2018) Clinical rating scales for urinary symptoms in parkinson disease: critique and recommendations. Mov Disord Clin Pract 5:479-491

17. Taylor CE, Arnold AC, Fu Q, Shibao CA (2020) Sex differences in cardiovascular autonomic control: introduction to the special issue. Clin Auton Res 30:365-367 